\title{
Dom Helder Camara e o AI-5: o estreitamento do espaço político doméstico e a exposição das demandas da sociedade brasileira no exterior (1968-1978)
}

\author{
Adenilson Ferreira de Souza ${ }^{*}$
}

\begin{abstract}
Resumo
O objetivo do presente artigo é analisar as principais demandas da sociedade brasileira transnacionalizadas por Dom Helder Camara (1909-1998), durante a vigência do AI-5 (1968-1978). O foco da análise orienta-se para as demandas da sociedade brasileira e não para as demandas pastorais, nacionais ou internacionais, da Igreja, ou para a necessidade de uma produção biográfica de Dom Helder. O contexto histórico é o do AI-5, instrumento constitucional que restringe o espaço de atuação dos atores em arena política doméstica. No quadro de um "silêncio" imposto pelos governos militares do período, torna-se fundamental a exposição dos desafios da sociedade brasileira - as reformas estruturais, o combate ao colonialismo, o desenvolvimento, a justiça social etc. - em arena política internacional. Assim exposto, assiste-se ao transbordamento da ação política de Dom Helder para além das fronteiras do país, resultante da adoção das demandas da sociedade brasileira como elementos essenciais de seus pronunciamentos.
\end{abstract}

Palavras-chave: Demandas transnacionalizadas; Dom Helder Câmara; Política nacional; AI-5.

\section{Introdução}

O objetivo do presente artigo é analisar as principais demandas da sociedade brasileira transnacionalizadas ${ }^{1}$ por Dom Helder Pessoa Camara ${ }^{2}$ durante a vigência do

\footnotetext{
* Mestre em Relações Internacionais pela Pontifícia Universidade Católica de Minas Gerais. Licenciado em História Pela Universidade Católica de Pernambuco e Bacharel em Filosofia e Teologia pela Faculdade Jesuíta de Filosofia e Teologia.

1 A expressão demandas transnacionalizadas promove a conjugação de dois termos semanticamente distintos. Em geral, a palavra demanda relaciona-se com o termo Estado, sociedade, instituições etc., e, entre outros significados, resguarda o sentido de carência, em sentido material, de necessidade, de desafio, de questão, de problemas fundamentais. O termo transnacionalização, no entanto, diz-se do movimento de transposição de fronteiras, por atores políticos e econômicos, para o exercício das mais diversas atividades. Portanto, entendo por demandas transnacionalizadas aquelas questões cruciais da sociedade brasileira [tais como reformas estruturais e desenvolvimento] expostas por dom Helder Camara na arena política internacional. A inversão dos termos forma a expressão transnacionalização de demandas, entendida como o processo de transposição de fronteiras das questões próprias da agenda política doméstica.

2 Helder Pessoa Camara nasceu em Fortaleza, Ceará, em 1909. Ainda em Fortaleza, fez os estudos eclesiásticos de Filosofia e Teologia. Em 1931, recebeu a Ordenação Presbiteral. Em 1935, o Pe. Helder foi convidado pelo então governador cearense Menezes Pimentel para ocupar as funções de Diretor da Instrução Pública do Estado. Desde então, passou a desenvolver ativa militância também na Ação Integralista Brasileira - AIB. Em 1936, foi transferido para o Rio de Janeiro, onde abandonou o seu ideário integralista. Entre 1947 e 1952, dirigiu e colaborou com as revistas Ação Católica e Assistente
} 
Ato Institucional $n^{\circ} 5$ - AI-5 $5^{3}$ (1968-1978). Trata-se, pois, de aprofundar os temas mais recorrentes nos pronunciamentos de Dom Helder Camara em contexto de estreitamento do espaço político doméstico. Sem lugar a dúvida, as questões expostas por Dom Helder na arena política internacional correspondem aos principais desafios da sociedade brasileira nas décadas de 1960 e 70.

A análise dos temas fundamentais presentes nos escritos de Dom Helder Camara centra-se em sua produção intelectual. Assim, não figura entre os nossos objetivos, nessa empreitada, estabelecer uma relação exaustiva entre seu pensamento e as reflexões de outros autores, mas analisar os principais temas de seus escritos, de modo a indicar a outros pesquisadores, a bibliografia pertinente ao desenvolvimento de outras pesquisas. A opção por restringir o material de estudo em nada prejudica a análise.

Ao término da II Guerra Mundial e com a deposição de Getúlio Vargas, em 1945, o Brasil experimenta a irrupção de mudanças de toda ordem e em todos os setores da sociedade, depois de décadas de um falso senso de estabilidade. Essas mudanças, e não necessariamente o processo da qual resultam, são analisadas por estudiosos brasileiros e estrangeiros (BAER, 1965; FURTADO, 1965; LOPES, 1967, 1968; SKIDMORE, 1967; BRUNEAU, 1974). Este último autor apresenta esboço do processo de mudança da sociedade brasileira e indica sua implicação para a Igreja.

As melhores descrições da política da Primeira República, ou da República Velha (1891-1930), são aquelas que sublinham o seu caráter descentralizado e flexível. A característica desse sistema parece ter sido a sua capacidade, de curta duração, de jogar com vários grupos e, no processo, manter o status quo. Thomas Bruneau descreve a Primeira República em termos de compromissos, equilíbrio e falta de mobilização:

Eclesiástico. Em 1952, Pe. Helder foi ordenado bispo auxiliar da Arquidiocese do Rio de Janeiro. Apenas dez dias após o golpe militar de 1964, dom Helder Camara assumiu a Arquidiocese de Olinda e Recife, coordenou a mesma até 1985 e permaneceu em atividade até 1998, ano de sua morte.

${ }^{3}$ O Ato Institucional n ${ }^{\circ} 5$ - AI-5 - foi promulgado pelo Presidente da República Costa e Silva no dia 13 de dezembro de 1968, um dia depois da votação, no Congresso Nacional, sobre a questão da suspensão da imunidade parlamentar. O resultado da votação surpreendeu o governo: 216 contra a suspensão da imunidade parlamentar e apenas 141 a favor. A diferença de 75 votos constituía vitória significativa para os que se opunham. Em muitos pontos o texto reiterava disposições dos primeiros atos institucionais, mas havia uma diferença: não se estipulava prazo para sua vigência. Seriam permanentes os controles e a suspensão das garantias constitucionais. O ano de 1968 foi decisivo para o confronto entre a oposição organizada, com seus representantes no Congresso Nacional, por intermédio do Movimento Democrático Brasileiro - MDB -, e o Estado de Segurança Nacional. No centro do debate estava o grau de repressão que deveria ou poderia ser empregado no controle da insatisfação popular. O povo brasileiro sofreu um dos mais duros períodos de repressão, tortura e perseguição política de toda a história do Brasil. Em sentido amplo, o AI-5 representou a suspensão das garantias constitucionais e o estrangulamento das instituições democráticas. 
A política se assentava sobre grupos políticos e econômicos extremamente descentralizados, que não encorajavam uma mais larga participação do povo, e o sistema político, no nível nacional, era equilíbrio entre certos Estados mais poderosos. Durante a maior parte desse período, a estabilidade política era um dado pacífico e não havia razão para mudança. (BRUNEAU, 1974, p.101)

A análise da sociedade brasileira no pós II Guerra evidencia o caráter paradoxal das mudanças. Em muitos setores, os passos eram tão largos que o país parecia empurrar um rolo compressor sobre os entraves estruturais do passado. Em outros setores, no entanto, havia a crise e a regressão. Isso significa que, no início dos anos 50, a falta de planejamento resumia a situação do país, que precisa modernizar-se, desenvolver-se, distribuir renda. "Política, econômica e socialmente, o Brasil foi tragado numa voragem de mudança frenética que culminou no golpe militar de 1964." (BRUNEAU, 1974, p.103) Para Wanderley Guilherme dos Santos, o golpe de 64 resultou de uma "paralisia decisória" (SANTOS, 1986, p.22) instalada no Congresso Nacional.

Na segunda metade da década de 50, o país se encontrava diante de alternativas que compreendiam, pelo menos, duas diferentes modalidades de desenvolvimento: "a primeira implicava a realização de transformações profundas na estrutura de produção, de distribuição da renda, da propriedade da terra", favorecendo a criação de um mercado interno amplo, produzindo acelerado crescimento do setor industrial da economia. "A segunda proposta era prosseguir com o desenvolvimento econômico dentro de modelo que permitisse a satisfação dos interesses internacionais - externos e internos à sociedade brasileira.” (LIMA, 1979, p.27) Essa alternativa pressupunha o desenvolvimento, sem transformação, da estrutura econômica e social do país. É o desenvolvimento econômico dependente-associado que o país implementa depois do golpe de 1964.

O Brasil dos anos 60 sustentava entraves estruturais dos anos 50, quiçá dos anos 40. No plano social, o Movimento Operário ${ }^{4}$ iniciava lento processo de ascensão, elevando quantitativa e qualitativamente o nível de suas reivindicações econômicas e políticas. Nesse processo de ascensão, mesmo com profundos limites políticos e

4 A formação da classe operária na América Latina remonta às décadas finais do século XIX (CASANOVA, 1987, p.42). No Brasil, o Movimento Operário se constitui a partir do surto industrial ocorrido pós I Guerra Mundial. Nos anos 50, o Movimento passa por um lento processo de ascensão, procurando desprender-se das amarras impostas pelo governo Vargas dos anos 40. À década de 60 corresponde o segundo período da industrialização brasileira, época de maior expressividade do Movimento Operário. 
organizacionais, o movimento operário brasileiro rompia com a camisa de força que lhe tinha sido imposta pela ditadura Vargas (1937-1945) através de legislação sindical corporativa. Criou-se o Comando Geral dos Trabalhadores - CGT -, ilegal, mas interlocutor, de fato, do governo. O esforço de aliança das esquerdas produz a Frente de Mobilização Popular e a Frente Parlamentar Nacionalista, que elaboraram bases unitárias de ação: as "reformas de base" .

Quando as forças sociais se confrontam num antagonismo maior, dois elementos se conjugam, acelerando a radicalização dos conflitos: primeiro, a participação política dos camponeses que, pela primeira vez, se mobilizaram nos Sindicatos $^{6}$ e Ligas Camponesas ${ }^{7}$ pela defesa dos seus interesses, isto é, a transformação na estrutura da propriedade da terra e uma maior participação política, que confluíam nas reivindicações da frente reformista; segundo, força social tradicionalmente conservadora, os católicos compareceram diluídos nas diversas agremiações políticas que se constituíam na cena política. Esse processo, que necessita ser ainda melhor estudado, provocou o deslocamento de núcleo progressista da hierarquia e dos leigos no sentido de integrar a frente reformista.

A cronologia dos acontecimentos políticos, no período de 1955 a 1964, ainda que simples, demonstra o caráter paradoxal do sistema político brasileiro. A ascensão de Kubistchek, em 1956, marcou o início do processo de industrialização inteiramente ajustado aos interesses do capital internacional. O governo de Kubistchek (1956-1960), do PSD, caracterizou-se "pelo rápido crescimento econômico e pela criatividade que resultou em inovações, como a construção da nova capital federal em Brasília e a criação da Sudene, a repartição incumbida de executar a política de desenvolvimento para o Nordeste brasileiro". (SKIDMORE, 1988, p.27)

Na primeira metade da década de 1960, o crescimento econômico, apoiado na

\footnotetext{
${ }^{5}$ Entre os anos de 1950 e 1970, a expressão reformas de base foi de uso corrente no meio acadêmico, em particular, entre os cientistas sociais, bem como no campo da atividade política, para significar a necessidade de reforma agrária, de reforma educacional, de modernização do Estado etc. - consideradas essenciais para o desenvolvimento econômico do país.

6 Os camponeses organizaram-se em sindicatos, apoiados, sobretudo, pela Igreja. O esforço de sindicalização rural, por parte da Igreja, expressava interesse pela manutenção de sua influência política e de controle do potencial revolucionário dos camponeses. Quando a Igreja pleiteia a libertação política, econômica e cultural do camponês, manifestou o interesse de coordenação do processo, no intuito de evitar que ele se voltasse contra a Instituição.

${ }^{7}$ Em meados dos anos 1950, as Ligas Camponesas constituíram-se, provavelmente, na primeira forma de organização política do homem do campo pela defesa de seus interesses, a saber: a transformação na estrutura da propriedade da terra e uma maior participação política. Embora tenha alcançado expressividade política nacional em torno de Francisco Julião, a iniciativa da Liga foi inteiramente de grupos de camponeses.
} 
produção industrial da segunda metade dos anos 50, cedeu lugar à crise. "Entre 1957 e 1961, a produção industrial cresceu num índice impressionante de 80\%." (FURTADO, 1965, p.89) Além disso, o país enfrentou um período de instabilidade política - a sucessão de Vargas, a renúncia de Jânio Quadros, as condicionantes para a tomada de posse de João Goulart, o golpe de 64 -, que, se não remontou a três décadas, ao menos teve origem no processo de sucessão do governo de Juscelino Kubitschek. Em 1964, viveu-se a transição política de governos populistas para o regime militar. O contexto de prolongada crise traduz a incapacidade do Estado de absorver os interesses antagônicos dos grupos em conflito.

Nesse contexto histórico, a arena política internacional caracterizou-se pela permanência da estratégia da Guerra Fria entre os Estados Unidos da América - EUA e a União das Repúblicas Socialistas Soviéticas - URSS. Na arena política regional constatou-se, de maior monta, a Revolução Cubana (1959) e seus desdobramentos. Diante desse quadro, o imperialismo dos EUA ampliou o horizonte da Guerra Fria, o que englobou a América Latina na estratégia de enfrentamento da ameaça comunista, precipitou a queda de governos populistas e subsidiou a tomada e a permanência, no poder, de governos autoritários e antidemocráticos. Como resultado, assistiu-se à queda simultânea das recém-nascidas democracias em quase todos os países do Continente.

Na política doméstica, a sociedade brasileira enfrentou uma transição política resultante de aliança entre civis e Forças Armadas. Nesse enquadramento político, sustentou-se, no Brasil, uma democracia às avessas. A tomada de poder de governo constitucional de João Goulart, em 1964, elevou ao Executivo, de forma sucessiva, personalidades oriundas do alto escalão militar. O poder de Estado, em termos de força repressiva, suplantou o processo em curso, de maior participação da sociedade brasileira no governo. O símbolo de maior expressão desse estreitamento da arena política doméstica foi o AI-5.

A promulgação do AI-5 impunha à sociedade brasileira restrições de toda ordem e restringia, inegavelmente, o espaço de atuação política dos atores em arena política doméstica, em particular, a atividade política da Igreja Católica no Brasil. Dom Helder Camara era, indiscutivelmente, a figura mais emblemática da Igreja no contexto das perseguições do regime militar brasileiro. O cerco à Igreja dificultava sua atuação política no país. Como consequência, assistiu-se ao transbordamento da ação política de 
Dom Helder $^{8}$ para além das fronteiras do país, resultante da adoção das demandas da sociedade brasileira como elementos essenciais de seus pronunciamentos.

O pensamento político de Dom Helder se constitui em confronto com a realidade brasileira. Além disso, as suas reflexões expressam uma profunda relação com os grandes eventos religiosos da década de 60. Na década de 1970, consolidaramse na América Latina, e não apenas no Brasil, as Comunidades Eclesiais de Base CEBs -, referendadas, do ponto de vista teológico, pela Teologia da Libertação - TdL. O Concílio Ecumênico Vaticano II (1962-1965) e as Conferências Gerais do Episcopado Latinoamericano e do Caribe (Medellín, Colômbia, 1968 e Puebla de Los Angeles, no México, 1979) representaram eventos de grande esperança de transformação da Igreja, nos quais se fez e se reafirmou sua "opção preferencial pelos pobres”, sem, no entanto, excluir os demais.

Os temas mais recorrentes nos pronunciamentos de Dom Helder Camara, durante a vigência do AI-5, identificam-se com as questões cruciais da sociedade brasileira, expostas pelo autor em arena política internacional. A análise dos referidos temas - 1) a necessidade de reformas estruturais; 2) o combate ao colonialismo interno e externo; 3) a integração regional e o desenvolvimento; 4) o estabelecimento de verdadeira ordem; 5) a promoção da justiça como condição para a paz -, se nos impôs a necessidade de visitar o Centro de Documentação Dom Helder Camara - CEDOHC do Instituto Dom Helder Câmara - IDHeC - em Recife, no ano de 2009. Limitamo-nos a analisar a documentação produzida por Dom Helder para fins de palestras, conferências, discursos proferidos sobretudo na Europa, nos Estados Unidos e no Canadá, entre os anos de 1968-1978. Excluem-se do material analisado, portanto, os textos poéticos e/ou homiléticos do autor.

\section{A necessidade de reformas estruturais}

Nas décadas de 50, 60 e 70, a necessidade de reformas estruturais ${ }^{9}$ constituiu-

\footnotetext{
${ }^{8}$ O AI-5 restringe o espaço de atuação política dos atores em território nacional. Ao ser impedido de manifestar-se nos espaços públicos, jornais, revistas, universidades etc., e ao censurar todos aqueles que escrevem a seu respeito, restou a Dom Helder explorar a arena política internacional como lugar privilegiado para expor as suas reflexões acerca da realidade brasileira e do Terceiro Mundo. Nisso consiste o transbordamento de sua ação política.

${ }^{9}$ O tema da reforma de estruturas, ou da reforma administrativa do Estado, constitui-se em questão central do pensamento político e econômico de Celso Furtado, o mais influente economista brasileiro das décadas de 1950 e 60. As obras do autor que melhor serve ao estudo dessa matéria são: Desenvolvimento
} 
se, para Dom Helder Camara, na principal demanda da sociedade brasileira. Todas as outras demandas decorreram dessa urgência em mudar estruturas sociais, econômicas, políticas, culturais e religiosas. A manutenção de determinadas estruturas pode acarretar, e não raramente acarreta, obstáculo ao desenvolvimento, em termos econômicos e humanos. A mudança de estruturas, não era reivindicada apenas no âmbito da política doméstica, mas ampliava-se à arena política regional, até alcançar o sistema internacional.

No âmbito da arena política doméstica, Dom Helder, em discurso na Pontifícia Universidade Católica de São Paulo, em 1969, aludia às últimas medidas do governo Costa e Silva, supostamente em favor das reformas de base, isto é, reforma agrária, reforma educacional etc. O cenário político das possíveis reformas é assim descrito:

\begin{abstract}
O governo sabe que lançou mão de poderes especialíssimos [AI-5] e há de reconhecer o desgaste perante a opinião pública democrática mundial do mais terrível dos controles sobre a Imprensa. As medidas de exceção foram adotadas, sobretudo, para tornar possíveis as Reformas de base? O governo deu a entender que sim, ao alegar que o Legislativo lhe negava os instrumentos indispensáveis à concretização das Reformas. Pessoalmente, não vejo como possamos prescindir da Imprensa e do Congresso. (CAMARA, 1969a, p.2)
\end{abstract}

O imperativo da mudança de estruturas injustas e opressivas não se impõs como exigência exclusiva sobre os países subdesenvolvidos. O esforço de mudança não se limitou à mera reforma de caráter superficial das estruturas vigentes. Em palavras do próprio Dom Helder, encontramos o seguinte argumento:

\footnotetext{
No mundo subdesenvolvido, esta verdade parece uma evidência. Se se olha o mundo subdesenvolvido, de qualquer ângulo - econômico, científico, político, social, religioso - chega-se a compreender que uma revisão sumária, superficial, não bastará, de modo algum. Deve-se ter em vista revisão em profundidade, mudança profunda e rápida - deve-se chegar a uma revolução estrutural. É menos fácil compreender que o mundo desenvolvido tenha, também, necessidade de revolução estrutural. (CAMARA: 1968a, p.2-3) A revolução, de que o mundo precisa, supõe mudança radical das estruturas econômicas e políticas, mas não haverá revolução estrutural, sem revolução cultural. (CAMARA, 1968b, p.6)
}

Importa ressaltar que, quando se comparam as ajudas recebidas pelos países subdesenvolvidos com as perdas sofridas por eles em consequência da deterioração dos

e subdesenvolvimento (1961); Dialética do desenvolvimento (1964) e Subdesenvolvimento e estagnação na América Latina (1966). 
preços de suas matérias-primas compreende-se que, de fato, a injustiça assumiu dimensões planetárias ${ }^{10}$. O problema então não é de ajuda, mas de justiça.

Para Dom Helder, as superpotências da época, os EUA e a URSS, condicionam a arrancada dos países subdesenvolvidos rumo ao desenvolvimento, a ajuda financeira e a transferência de tecnologia. Quanto ao posicionamento dos governos latinoamericanos, Dom Helder observa que: "receosos de perder os dólares largamente anunciados e parcamente entregues, há governos que se contentam em promulgar leis de reformas de base e em criar vários órgãos para aplicá-las, deixando tudo, no entanto, cuidadosamente no papel". (CAMARA, 1968b, p.3) A estratégia sensata dos países pequenos e fracos não deveria girar em torno de supostas ajudas a receber, mas exercer pressão contra os gigantes de pés de barro, exigindo "revisão da política internacional do comércio ${ }^{11 "}$, elaborada pelos países ricos e responsável por estipular o preço tanto das matérias-primas dos países pobres, quanto dos produtos industrializados dos países ricos. A manutenção desse monopólio perpetua a injustiça internacional geradora de violência e de guerras.

A mudança das estruturas em âmbito nacional e internacional tem como resultado previsível, o resgate da dignidade humana de bilhões de pessoas em situação subumana. "Os países ricos baseiam a própria riqueza em injustiças institucionalizadas. Os ricos, dos países desenvolvidos, e mesmo os ricos dos países pobres, ignoram conscientemente a exploração de concidadãos, submetidos à vida de miséria e pobreza". (CAMARA, 1977, p.3) A manutenção do status quo geralmente se sustenta mediante política repressiva de governos autoritários e antidemocráticos, sob "pretexto de perigo comunista." (CAMARA, 1972a, p.3) A revisão de "conceitos equivocados [tais como: super-produção ou sub-consumo, explosão demográfica, livre comércio], de consequências desastrosas para mais de 2/3 da humanidade" (CAMARA, 1974, p.4), evidenciaria as injustiças da política internacional do comércio e, no plano doméstico, a má distribuição de renda dentro dos próprios países.

Os países pequenos ou fracos, sempre que forçam revisão de comportamento dos países ricos e fortes, inegavelmente, encontram-se sujeitam-se a sanções ou a

\footnotetext{
${ }^{10}$ As ajudas dos países ricos aos países pobres são consideradas necessárias, porém, insuficientes. Além disso, constata-se que tais ajudas são feitas ao preço de injustiças terríveis ou à custa do agravamento da miséria imposto pela política internacional do comércio.

${ }^{11}$ A política internacional do comércio - monopolizada, inicialmente, pelos antigos trustes, e, mais recentemente, pelas multinacionais ou transnacionais, com sede nos países desenvolvidos -, é responsabilizada por dom Helder, pela prática do colonialismo externo, enquanto política dos grandes impérios, e pela manutenção de injustiças entre países e mesmo entre continentes.
} 
retaliações. Entretanto, quando tais países ousam recorrer aos mesmos métodos de defesa de seus interesses econômicos, através de novos cartéis, contra o cartel estabelecido pelas potências, são responsabilizados pela ameaça à ordem mundial e à estabilidade do sistema financeiro mundial. A atuação da Organização dos Países Produtores e Exportadores de Petróleo - OPEP -, em 1973, é representativa desse quadro de questões.

O perfil de atuação da Opep encerrou grandes surpresas pelo seu ineditismo nos tempos modernos. Nações islâmicas - Argélia, Arábia Saudita, Irã, Líbia, Síria, Iraque, Egito -, uniram-se a países da América Latina, como a Venezuela, e a países da África. O ineditismo repousa exatamente no fato de terem conseguido "superar tantas diferenças culturais, religiosas, interesses econômicos particulares" (CAMARA, 1975a, p.5-9), em vista de questão global de redefinir o preço do petróleo no mercado internacional. Pela primeira vez, em muitos séculos, o núcleo do poder econômico é seriamente ameaçado.

No âmbito regional, a mudança de estruturas implicou novo posicionamento da Religião perante as questões sociais e políticas. Ao líder religioso fez-se necessário deixar o altar, ganhar as periferias dos grandes centros, despertar os camponeses do sono profundo da exploração, distanciar-se dos donos do poder. Então, tornou-se relevante a parcela de responsabilidade que competia, em particular, aos cristãos do Continente. Pois,

\begin{abstract}
Somos a parte cristã do Terceiro Mundo. Que triste testemunho para os nossos Irmãos não-cristãos do Terceiro Mundo apresentar nosso Continente Cristão com mais de $2 / 3$ de população em situação sub-humana. $O$ fato é que nos preocupamos, de tal sorte, com a manutenção da ordem social que nem percebemos que ela era muito mais desordem estratificada. (CAMARA, 1971a, p.2-3)
\end{abstract}

Nesse caso, as disputas internas à própria Igreja Católica precisaram ser amenizadas em prol da implementação de uma ação em conjunto. O pressuposto fundamental da atividade era a reforma de estruturas. $\mathrm{O}$ objetivo principal, a promoção humana de miseráveis. O meio mais eficiente, a ação política articulada de cristãos e não-cristãos:

Se quisermos evitar que o chamado Continente Cristão se entregue à radicalização e à violência, caia no caos, temos que nos unir - cristãos de todas as denominações, homens de boa vontade mesmo não-cristãos e até não religiosos - para tentar chegar a tempo. Se todos clamarmos por reformas 
estruturais, pelo fim da escravidão, pelo fim das condições sub-humanas, pela promoção humana dos miseráveis, os privilegiados e as autoridades não terão condições de dizer que nos tornamos comunistas e subversivos. (CAMARA, 1971a, p.4)

Não é radicalizando, extremando, rompendo, que conseguiremos mudar o que deve ser mudado nas estruturas da Igreja. (CAMARA, 1972b, p.2) A possível mudança de estrutura poderia partir da Comunidade de Base $^{12}$. Em palavras do próprio Dom Helder: "as Minorias Abraâmicas ${ }^{13}$ sentem, pressentem que o segredo para a mudança das estruturas da Igreja está em Comunidades de Base, que tentam concretizar os grandes textos ${ }^{14}$ e as belas conclusões do Vaticano II." (CAMARA, 1972c, p.5)

A mudança de estruturas nos países subdesenvolvidos supõe, indubitavelmente, a mudança de estruturas nos países desenvolvidos. A partir daí, o desafio é imperioso:

O difícil começa quando se precisa dizer que esta mudança de estruturas nos países pobres supõe, exige mudanças de estruturas nos países de abundância. Mudar por que, se as estruturas vigentes conduziram os países ricos à sua prosperidade atual? Que se pense em ajuda, mesmo larga e generosa, e a compreensão será fácil. Exigir de ir mais longe, é criar inutilmente irritações. (CAMARA, 1971b, p.5)

A mudança das estruturas socioeconômicas e político-culturais, no Brasil e na América Latina, "só poderá ser feita sem violência, se houver clima para uma democrática, equilibrada e firme pressão moral libertadora"15. (CAMARA, 1969a, p.6) A pressão moral libertadora, tal como compreendida por Dom Helder, goza de força

\footnotetext{
${ }^{12}$ A Comunidade de Base, ou Comunidades Eclesiais de Base - CEBs -, surge no Brasil e na América Latina como um fenômeno religioso ocorrido no interior da própria Igreja Católica no final dos anos 50, mas que logo recebe contornos de movimento social. Nos anos 60, mas sobretudo na década de 70, as CEBs ganham expressão política dentro e fora da Igreja, tendo como método a reflexão crítica do Evangelho e como foco principal a conscientização das massas. Não sendo as CEBs um movimento sindical nem sequer um partido político, mas um movimento surgido no seio da Igreja com espírito renovador e desejoso de maior comprometimento social, dom Helder considera as CEBs como possível agente da mudança das estruturas. Portanto, as CEBs representam a grande esperança da Igreja em seu intento de modernização.

${ }^{13}$ A expressão Minorias Abraâmicas é usada por dom Helder Camara para definir pessoas ou pequenos grupos de pessoas, espalhadas por todo o mundo, porém, carentes de organização para empreender força similar à da bomba atômica contra os promotores de violência, guerras e injustiças, através de movimento pacífico de pressão moral libertadora.

${ }^{14}$ Os grandes textos aqui não são os livros sagrados nem os documentos dos Padres da Igreja, mas as Encíclicas Mater et Magistra (1961), Pacem in Terris (1963) e Populorum Progressio (1967). As duas primeiras publicam-nas o papa João XXIII e a última fez-se publicar o papa Paulo VI.

${ }^{15}$ A expressão pressão moral libertadora é usada isolada ou conjuntamente com a expressão força moral; sempre entendidas como instrumento capaz de constranger os países ricos, ou os ricos dos países ricos, ou os ricos dos países pobres, quando perseguem avidamente o objetivo de explorar os pobres - países, regiões, indivíduos -, e forçar mudança de estruturas.
} 
capaz de revolver, pacificamente, as estruturas de opressão e de injustiças, e tem sua origem na mobilização das Minorias Abraâmicas, pessoas espalhadas por todo o mundo, amantes da justiça.

\section{O combate ao colonialismo interno e externo}

Na década de 60, o mundo assistiu ao processo de descolonização política da África. Contudo, os recém-nascidos estados africanos, somados aos já centenários estados latinoamericanos e asiáticos, careciam de independência econômica. O colonialismo $^{16}$ constitui-se, para Dom Helder Camara, num dos principais entraves ao desenvolvimento das economias dos países atrasados, em termos de desenvolvimento humano, de crescimento econômico e de evolução cultural.

O fenômeno do colonialismo, ${ }^{17}$ como compreendido por Dom Helder, existe na relação entre as regiões do mesmo país, entre países da mesma região e até mesmo entre continentes. Assim, o colonialismo interno ${ }^{18}$ expande seus tentáculos para além das fronteiras do país, em razão do vínculo estabelecido entre as elites dos diferentes países. No entanto, o colonialismo externo, dos trusts internacionais ${ }^{19}$ expande seus tentáculos na direção dos países, em geral, produtores de matérias-primas e consumidores de produtos industrializados. As multinacionais, em virtude de suas próprias características, colonializam países, regiões, continentes inteiros.

O colonialismo se estabelece por meio de práticas profundamente enraizadas na cultura dos povos dominantes e dominados. Aos povos dominantes, pela convicção do eterno direito de expansão ou, pelo menos, da manutenção de suas riquezas, não se importando com o custo da exploração. Aos povos explorados, pela sensação de ser esta

\footnotetext{
${ }^{16}$ Os termos colonialismo interno ou externo são fartamente utilizados por dom Helder Camara para explicar a exploração dos continentes ricos sobre os pobres, dos países ricos sobre os pobres, das regiões ricas sobre as pobres, dos ricos dos países pobres sobre os seus concidadãos.

${ }^{17}$ Embora os mais destacados cientistas sociais brasileiros já não usassem mais o termo colonialismo, mas preferissem as expressões economia dependente ou interdependência política e/ou econômica, a exemplo de Caio Prado Jr., Celso Furtado, Wanderley Guilherme dos Santos, dom Helder permanece denunciando o colonialismo como uma realidade inequívoca na relação entre regiões, países e Continentes.

18 A expressão colonialismo interno relaciona-se, nos textos de dom Helder, com a expressão colonialismo externo ou neocolonialismo, enquanto fenômenos considerados a partir de problemas conjugados - a exploração de mão-de-obra, de matérias-primas, de mercado, de capital financeiro etc.

${ }^{19} \mathrm{O}$ processo de implantação, funcionamento e expansão dos trusts internacionais em direção aos países subdesenvolvidos é descrito de forma recorrente nos textos de dom Helder. Contudo, desde 1970, o termo trusts cede lugar aos conceitos plurinacionais, multinacionais e transnacionais, respectivamente.
} 
a ordem do mundo, em alguns casos, de ser esta a ordem querida por Deus. Quando emerge entre os povos colonizados o anseio de liberdade, a reação imediata dos grupos dominantes caracteriza-se pelo combate ideológico ou pelo conflito armado para a manutenção da ordem.

O colonialismo, em qualquer de suas vertentes, traduz-se em exploração de pessoas, grupos, povos, sociedades, países, continentes. O pensamento de Dom Helder pode nos oferecer o escopo do fenômeno:

Há o fenômeno chamado colonialismo interno: em regiões subdesenvolvidas, em áreas de miséria há privilegiados ${ }^{20}$ cuja fortuna é mantida à custa da miséria de milhões. Latifundiários mantêm inexplorada a maior parte de suas terras. Permitem que nelas morem e trabalhem famílias pobres. Mas, para que não adquiram direitos, são mantidas, cuidadosamente, em casebres infectados e trabalham em regime patriarcal, sem lei nenhuma que os ampare. Indiscutível situação infra-humana. (CAMARA, 1968c, p.2)

O colonialismo interno não é um fenômeno abordado por Dom Helder como problema estritamente de política doméstica. É um problema de fato a ser combatido desde a política doméstica, porém, o enfrentamento dessa prática não se limita apenas a iniciativas esboçadas no interior das fronteiras de um determinado Estado. Os trusts internacionais entrelaçam empresas de diversos ramos em diversos países e, além de darem origem às grandes empresas transnacionais, promovem o surgimento de problemas igualmente transnacionais. Aos trusts são atribuídas as mais profundas estruturas de injustiças.

Ao analisar o contexto sócio-político-econômico latinoamericano, Dom Helder formula resposta para a seguinte indagação: há, na América Latina, o contexto propício e as condições favoráveis para algum tipo de resistência radical contra o colonialismo interno de efeitos e de consequências desumanizadoras? O resultado da análise de conjuntura regional que nos chega é:

As massas latinoamericanas - mal alimentadas, mal vestidas, sem habitação, sem mínimo de condições de educação e de trabalho, vivendo uma religiosidade fatalista e mágica - não tinham sequer condições de rebelar-se. Encontram-se incapacitadas para uma resposta autêntica. ${ }^{21}$ Mas, assim como

\footnotetext{
20 Atualmente, preferimos o termo elites, nacionais ou internacionais, para caracterizar os grupos dominantes das várias dimensões da sociedade brasileira e/ou mundial. O termo usado por dom Helder, não raramente com conotação pejorativa, é o de privilegiados.

21 As massas da América Latina, e também do Terceiro Mundo, veem-se incapacitadas de qualquer autêntica resposta em virtude de sua condição de vida, a miséria, que ocupa naturalmente o centro de suas preocupações. Além disso, pressupõe-se por resposta autêntica capacidade de organização e de
} 
os Negros norte-americanos foram impelidos à violência, vive-se, na América Latina, um clima de pré-revolução, consequência da cegueira e do egoísmo de Governos e Poderosos. (CAMARA, 1968c, p.2)

O estado de inércia das massas populares pode ser estendido a todo o Terceiro Mundo. A impotência causada pela miséria não se restringe à realidade da América Latina. Assim, pode-se observar que:

No Terceiro Mundo, as massas, esmagadas pelo colonialismo interno e pelo neocolonialismo, caíram no fatalismo, na falta de esperança, no medo. Não são capazes, por enquanto, de entender, de modo total, o dom divino da liberdade. Acham-se atrofiadas pela miséria e domesticadas pela cultura do silêncio. A liberdade, para elas é ainda desejo vago, informulado. Sem dúvida, em potencial são verdadeiros homens, mas são homens em cujo seio, dormem a consciência social e a ideia de liberdade. (CAMARA, 1971b, p.1)

O cristianismo passivo que se propagou na América Latina, desde o início da colonização, no séc. XVI, é reconhecido e duramente responsabilizado, por Dom Helder, pela inércia das massas marginalizadas no Continente.

O Cristianismo que difundimos no Continente superestimou a salvaguarda da ordem estabelecida; insistiu em virtudes como a paciência, a obediência, a aceitação e a oferta dos sofrimentos. Sentimos que é inadiável que sejamos [nós cristãos] os primeiros a dar exemplo de libertar-nos das estruturas cuja superação é básica para que haja, no Continente, desenvolvimento com justiça. (CAMARA, 1968c, p.5)

A insensibilidade das elites dos países pobres perpetua a situação de miséria de milhares de concidadãos. Embora os privilegiados elaborem leis e criem órgãos para aplicá-las, em tempo oportuno, reagem a qualquer sinal de seus efeitos:

\footnotetext{
Os privilegiados dos países pobres nem percebem que deixam à margem da vida econômico-social e político-cultural a maior parte da população do país. E torna-se impossível qualquer mudança de estrutura. Os privilegiados aceitam leis de reforma de base e a criação, pelo Governo, de órgãos para aplicá-las. Só não aceitam que alguém se decida mesmo a levar à prática qualquer mudança em profundidade. Mudanças, sim, mas prudentes, graduais. (CAMARA, 1970a, p.2)
}

Ao constatar a dramática situação dos pobres nos países sul-americanos, Dom Helder adverte: "não nos cansemos de denunciar que há em nosso Continente o pior dos Colonialismos: o interno". (1971c, p.2) Os colonialismos interno ou externo, através de revolução armada, pois dom Helder se mostra convicto da ineficácia deste recurso. 
seus grupos dominantes, resistem a toda e qualquer tentativa de mudança de estruturas e, por conseguinte, esforçam-se com denodo pela manutenção do status quo. O combate profundo e irreversível do colonialismo implica em mudança de estruturas, inclusive com a promulgação de novas leis, pelo governo, em favor das reformas de base.

O enfrentamento do colonialismo interno e externo conjuga-se com as iniciativas de mudanças estruturais, mas, sobretudo, de revisão na política internacional do comércio. Assim, a superação do colonialismo resulta de transformações de estruturas de âmbito sistêmico. As medidas de combate ao colonialismo precisam ser de tal forma abrangentes que atinjam, a um só tempo, a política doméstica e o sistema político internacional.

\section{A integração regional e o desenvolvimento}

\section{A integração regional}

Os entraves à efetiva integração política dos países do Continente sulamericano são compreendidos por Dom Helder como reflexos dos desafios a serem superados na relação entre grupos de interesses internos a cada país da região - isto é, o colonialismo interno -, e do Brasil em particular, com regiões marcadas por contradições, dificuldades e perspectivas distintas. A questão do desenvolvimento nacional e regional, no entanto, entende-se como desenvolvimento integral e autêntico. ${ }^{22}$ Integral porque abrangente. Autêntico porque verdadeiro e continuado.

Não compete à Religião, em qualquer de sua denominação, elaborar programa de governo para o desenvolvimento de determinado país, região ou continente. Embora não elaborasse um projeto específico para o desenvolvimento e a integração políticoeconômica dos países sul-americanos, a Igreja Católica expressa, em diversas ocasiões e por meio de alguns documentos, o interesse em participar do processo, que, ao término, espera-se implementar mudanças estruturais profundas e irreversíveis no Continente. Em palavras do Conselho Episcopal Latino-americano e do Caribe - CELAM -, verifica-se que:

\footnotetext{
${ }^{22}$ As expressões desenvolvimento integral ou desenvolvimento integral e autêntico aparecem geralmente acompanhadas da advertência de que tal desenvolvimento não se faça a preço desumano ou à custa de injustiças terríveis.
} 


\begin{abstract}
A integração da América Latina é um processo em marcha e de caráter irreversível; constitui instrumento indispensável para o desenvolvimento harmônico da região. A Igreja pode contribuir [quer comprometer-se] para o ideal de integração. É necessário elaborar e difundir uma doutrina capaz de orientar o processo da integração. Como testemunho, integrar a Igreja mesma em seus diferentes níveis; elaborar pastoral de conjunto em nível continental. Por fim, estimular os que promovem a integração - organizações e instituições. (CELAM, 1966, p.13-14)
\end{abstract}

A Igreja latino-americana, ao menos em documento, não quer apenas manifestar boa vontade, mas expor seu modo de participação no processo de integração:

\begin{abstract}
A Igreja pode desenvolver ação estimulante no processo de integração da América Latina, especialmente pela instauração de espírito de solidariedade. Consideram-se como medidas fundamentais: a integração das populações dentro de cada país; a integração de regiões de países vizinhos; a promoção de autênticas reformas estruturais; estimular a realização de estudos que mostrem o quadro da realidade latino-americana; apoiar os organismos que se ocupam da integração latino-americana. (CELAM, 1968, p.23-25)
\end{abstract}

A América Latina deve, em bloco, adotar uma postura de valorização de suas matérias-primas. Para tanto, precisa optar por uma estratégia de cooperação entre os países da região:

Se a América Latina se unisse de verdade, sem ódio a ninguém, mas decidida a usar a cabeça e a não ser mais idiota; se a América Latina se completasse como um todo, sem patrões de fora, nem patrões de dentro, mudaríamos o mapa das operações. Sem dúvida, temos problemas imensos a enfrentar. Mas no dia em que decidíssemos que matéria-prima nenhuma partiria daqui sem ao menos um começo de industrialização, abalaríamos as superpotências. (CAMARA, 1971d, p.2-3)

No início da década de 1970, as superpotências da época, EUA e URSS, e as potências médias europeias esforçaram-se para cooptar os países de maior influência regional. A essa estratégia política Dom Helder formula o seguinte comentário:

Esperemos que o sentido do ridículo nos salve. Integração latino-americana todos desejam. Não faltará quem nos instigue, quem nos provoque e nos leve, inclusive, a corridas armamentistas, e, se não usarmos a cabeça, a choques e, quem sabe, a guerras que só serviriam aos grandes. (CAMARA, 1971d, p.2)

No que tange à reintegração de Cuba na Organização dos Estados Americanos - OEA -, Dom Helder pede que se respeite sua escolha de regime político com base no princípio de autodeterminação dos povos: 
Tentemos organizar e conduzir, com segurança, nos USA e nos Países latinoamericanos, movimento tendente a reintegrar, na Comunidade Americana, Cuba, respeitando-lhe a opção política e a autonomia de Nação soberana. Quanto mais persistirem o bloqueio econômico e a excomunhão continental, mais fortemente estaremos acuando um Povo. Não se pode condenar Nação inteira a viver num gueto. (CAMARA, 1969b, p.4)

A integração político-econômica da América Latina é pensada em termos de socialização dos recursos naturais e dos benefícios resultantes do processo de industrialização e da comercialização dos produtos no mercado regional e internacional. Assim, o processo de integração não é definido em termos de livre mercado, em perspectiva do liberalismo radical.

\section{O desenvolvimento}

Em diferentes países do mundo, Dom Helder critica a ideologia segundo a qual o subdesenvolvimento dos países pobres relaciona-se com o tipo racial, a indisposição para o trabalho, o princípio da desonestidade e o crescimento demográfico. O combate a esse pensamento se constata pelo argumento:

\footnotetext{
Nos países desenvolvidos, quando se pensa nos países pobres, a tentação é imaginar que, no fundo, no fundo, há um problema racial, agravado pela falta de coragem de trabalhar, pela desonestidade e, sobretudo, nos últimos tempos, pela explosão demográfica. Mesmo se fossem válidos [estes conceitos ou preconceitos], não deveriam ser pretexto para esquecer que há capitais de impérios onde se decide a política internacional. (CAMARA, 1970b, p.4)
}

Assim sendo, é equívoco perigoso pensar em termos de superioridade racial, de desonestidade e de explosão demográfica. Nesse caso, Dom Helder sugere:

É preciso ajudá-los a compreender e a aceitar que a riqueza dos países desenvolvidos se alimenta da miséria dos países pobres. É preciso desmontar a inverdade do racismo e fazer ver que se os brancos ficassem sem saúde, sem alimentação, sem roupa, sem casa e sobretudo sem esperança, perderiam a coragem e, também eles, pareceriam preguiçosos. É preciso demonstrar que os desonestos, nos países pobres, são, quase sempre, traidores, corrompidos pelo dinheiro de fora. (CAMARA, 1970c, p.2)

O problema demográfico existe, mas está longe de ser o âmago do problema do desenvolvimento. (CAMARA, 1970d, p.2) O problema do subdesenvolvimento resulta, de fato, da "injusta política internacional do comércio". Além disso, "os dois obstáculos para que os países pobres se arranquem do subdesenvolvimento e da miséria são: o 
colonialismo interno e o neocolonialismo externo". (CAMARA, 1971e, p.3)

De acordo com Dom Helder, "a finalidade a atingir é o desenvolvimento integral, isto é, o desenvolvimento do homem todo e de todos os homens". E acrescenta:

Em nossos dias, não há apenas indivíduos e grupos pobres, mas países e continentes, que mergulham no subdesenvolvimento e na miséria. As ajudas dos países ricos são necessárias, mas não bastam: é preciso atingir o âmago do problema - as injustiças na política internacional do comércio. (CAMARA, 1970e, p.1)

Quanto ao comportamento das multinacionais que pretendem colaborar com o desenvolvimento do Continente, a observação de Dom Helder, embora sujeita a críticas, sobretudo por sua análise superficial, oferece os seguintes elementos:

As macro-empresas que vieram salvar a América Latina da cubanização, de fato deixam o Continente ainda mais escravo: com a colaboração preciosa da CIA, especialista em descobrir e alardear infiltrações comunistas, obtêm o adiamento das reformas de base; com a colaboração do FMI, obtêm a adoção, pelos países subdesenvolvidos, de modelos neocapitalistas de desenvolvimento, e promovem apenas o crescimento econômico de grupos privilegiados; com a colaboração de Bancos Comerciais, de Bancos de Investimentos, de Companhias de Seguros e de Fundos Mútuos de Investimentos, mantêm u'a falsa mística de desenvolvimento. (CAMARA, 1972d, p.4)

Ao constatar falsa mística de desenvolvimento, Dom Helder sugere a substituição do conceito de desenvolvimento pelo de libertação.

\footnotetext{
Desenvolvimento! Esta bela expressão despertou tanta esperança no Mundo! Como é fácil entender os que sentem necessidade de um novo nome, por exemplo, libertação! - dado que, no início da $2^{a}$ década do desenvolvimento, mais de $2 / 3$ dos países do Terceiro Mundo já se consideram, melancólicos, em um $4^{\circ}$ Mundo, o mundo dos que não têm a menor chance de arrancar-se da miséria e de partir para o desenvolvimento. (CAMARA, 1973, p.5-6)
}

Em suma, o desenvolvimento, integral e autêntico, pode arrancar pessoas e povos da miséria, da violência, da debilidade, das deformações psicofísicas, da morte, das guerras, e é capaz de lançar os seres humanos em direção ao que poderíamos sustentar como a condição de dignidade humana.

\section{O estabelecimento de uma "verdadeira ordem"}

A análise sócio-política da sociedade brasileira, das décadas de 1950, 60 e 70, nos impõe a necessidade de formulação do seguinte questionamento: o que se vive no 
Brasil, e por extensão também na América Latina e nos demais países subdesenvolvidos, constitui-se em ordem social ou em desordem estabelecida? ${ }^{23}$ Qual é o determinante no modo de atuação da Igreja? Qual é a postura do governo diante de sociedade caracterizada por profundas contradições?

O colonialismo interno empenha-se incansavelmente na manutenção das estruturas que garantem privilégios e uma pseudo-ordem social. Qualquer iniciativa em favor da mudança de estruturas é interpretada pelos grupos dominantes como ameaça à ordem social ou à estabilidade. A manutenção de estruturas, que sustenta um determinado tipo de ordem social, por seu turno, gera inúmeras injustiças. A conscientização da situação de injustiça, resultante do processo de libertação cultural, questiona a ordem social estabelecida.

Segundo Dom Helder, "a Igreja, tradicionalmente, participava desta preocupação com a ordem social e com a salvaguarda da propriedade privada e do respeito às autoridades constituídas". (CAMARA, 1970a, p.2) Internamente, "muitos líderes cristãos se deixam abalar pelo receio de que mudanças rápidas perturbem a 'ordem social', firam o princípio de autoridade, derrubem a propriedade privada." (CAMARA, 1970b, p.3 - grifos do autor)

Mas, "nos países subdesenvolvidos, implantam-se, com facilidade, regimes de força, a pretexto de salvar a ordem social” das investidas da subversão e do comunismo. A delação é insuflada. "A tortura ${ }^{24}$ é utilizada como método científico para arrancar declarações dos 'subversivos' ou supostos subversivos." (CAMARA, 1970f, p.2) Assim, torna-se quase impossível fazer oposição ao governo, em regime antidemocrático, e eximir-se da acusação de subversivo.

Ordem é, para Dom Helder, "a disposição das pessoas e das coisas no lugar que lhes cabe”. (CAMARA, 1971e, p.1-5) A ordem social, no entanto, por ser percebida em uma perspectiva política:

\footnotetext{
A Igreja Cristã, especialmente a Católica que é a dominante, preocupou-se tanto em manter a ordem social e a autoridade, que nem percebeu que se tratava muito mais de uma desordem estabelecida, de uma injustiça estratificada. E a Igreja insistiu tanto em virtudes passivas, como paciência, aceitação da vontade de Deus, aceitação dos sofrimentos em união com os de Cristo, que, na prática, demos razão a Karl Marx, pregando uma religião como ópio para o Povo. (CAMARA, 1971c, p.2)
}

\footnotetext{
${ }^{23}$ A expressão desordem estabelecida geralmente aparece, nos escritos de dom Helder, acompanhada da expressão injustiça estratificada, ou ainda da expressão injustiça institucionalizada.

${ }^{24}$ Os relatórios da Amnesty International de 1970 e 1973 denunciam torturas no Brasil. Entretanto, depoimentos de torturados podem ser encontrados em Brasil: nunca mais (2001).
} 
A manutenção de ordem injusta sustenta, na verdade, algum tipo de desordem institucionalizada. Contudo, "quando a Igreja se mobiliza na direção das reformas estruturais, as elites e, por vezes, Governos do Continente estranham o modo de atuação da Instituição". Apreciavam a Religião que garantia a situação de privilégio. "Consideram intromissão indébita da Igreja, perturbação da ordem, subversão, jogo do comunismo falar em educação libertadora e em mudança das estruturas de escravidão". Julgam que "aquilo que levou séculos se consolidando não pode ser mudado em dias, em semanas, em meses, e nem mesmo em anos". Nada de revolução, no sentido de uma mudança rápida e profunda, por mais que se pretenda revolução na paz. "Só admitem que se fale em evolução progressiva, gradual, paciente." (CAMARA, 1971a, p.3)

O esforço de manutenção das estruturas pode gerar no Continente ambiente propício para o conflito armado e, por conseguinte, conduzir ao caos social. Porém,

Se quisermos evitar que o chamado Continente Cristão se entregue à radicalização e à violência, caia no caos, temos que nos unir - cristãos de todas as denominações, homens de boa vontade mesmo não-cristãos e até não religiosos - para tentar chegar a tempo. Se ao invés de pequeno grupo, todos clamarmos pelo fim da escravidão, pelo fim das condições sub-humanas, pela promoção humana de milhões, os privilegiados e as autoridades não terão condições de dizer que todos nos tornamos comunistas e subversivos. (CAMARA, 1971a, p.4)

Para Dom Helder, "ao menos no Brasil, a ordem social existente, de ordem só tem o nome". (CAMARA, 1975b, p.2) No entanto, a reação dos grupos dominantes contra denúncias de opressão e de exploração é previsível. Quanto à força mobilizada, equivale a toda força de que dispõem. Então,

Como anunciar a decisão de trabalhar, de maneira pacífica, para animar as massas marginalizadas do nosso continente sem contar com represálias de quem não admite perder os privilégios? Como questionar a ordem estabelecida e espantar-se vendo a reação estalar? Como criar condições para nossa gente se organizar, adquirir consciência crítica, pretender participar de decisões, caminhar com os próprios pés e pensar pela própria cabeça, e não contar com tempestades? (CAMARA, 1975b, p.2)

É bem provável que Dom Helder pensasse em "nova ordem econômica mundial" (CAMARA, 1976, p.1-6) resultante de profunda transformação nas estruturas do sistema internacional. Apenas isso justificaria a sua proposta de substituição do conceito de desenvolvimento pelo conceito de libertação. 


\begin{abstract}
Abandonemos, sempre mais, a expressão "desenvolvimento", expressão que nos foi tão cara, que acendeu tanta esperança no mundo, mas gastou-se depressa. E adotemos, sempre mais, uma nova expressão, que seja nossa nova bandeira de luta pacífica: a "libertação". Libertação das estruturas de escravidão! Libertação dos racismos! Libertação das guerras! Libertação da miséria, como a pior, a mais hipócrita e mais sangrenta de todas as guerras! (CAMARA, 1972e, p.6-7 - grifos do autor)
\end{abstract}

É bem verdade que desde o início da década de 1960, colocou-se em evidência na América Latina, uma nova vertente teológica internacionalmente conhecida como Teologia da Libertação. Em alguns de seus escritos, particularmente nas Circulares conciliares, Dom Helder reconhece não ser teólogo da libertação, e não o é de fato, em sentido estrito. Entretanto, nenhum teólogo da libertação excluiria Dom Helder do círculo dos representantes ativos da prática teológica da libertação.

Em suma, da conjugação da ordem social com a estabilidade políticoeconômica, espera-se a construção de uma sociedade harmônica, com desenvolvimento humano e crescimento econômico resultantes de profundas reformas estruturais e de mudança de mentalidades. Tudo isso se fará numa estreita cooperação entre governos, organizações e instituições transnacionais. "A ajuda [dos países ricos] é indispensável, urgente, necessária para defender a justiça como condição de paz", mas é em absoluto insuficiente. Por essa razão, "trabalhar pela justiça é trabalhar pela paz". (CAMARA, 1970e, p.4)

\title{
A promoção da justiça como condição para a paz
}

A repressão do regime civil-militar brasileiro de 64, sobretudo a partir da promulgação do AI-5, institucionalizou a violência. A oposição, por sua vez, dividiu-se e adotou estratégias distintas de resistência. Se adequado fosse aplicar às oposições a tradicional classificação de radical e moderada, a esquerda radical armaria-se e ensaiaria uma resistência mais efetiva à força do governo, de potencial inequivocamente esmagador; a esquerda moderada, no entanto, estenderia suas ações até o limite do marco constitucional. Nessa confrontação de forças e poderes entre governos e oposições ressignificava-se o conceito de paz, em Estado de exceção, no Brasil.

A noção de paz, tal como formulada e propagada por Dom Helder, é vinculante dos conceitos de "desenvolvimento integral e autêntico", de segurança e de justiça. Apoiado na Populorum progressio, de Paulo VI, de 1967, n. 87, Dom Helder Camara promove a noção de que "o desenvolvimento é o novo nome da paz". (CAMARA, 
1970g, p.2) A correlação de maior predominância, em quase todos os seus pronunciamentos, é a da “justiça como condição para a paz.” (CAMARA, 1968c, p.1)

Afirmar que o fundamento da justiça, para Dom Helder, encontra-se em princípio religioso - isto é, amor ao próximo como expressão do amor a Deus, em virtude de sua participação numa hierarquia religiosa e de compromissos assumidos pautados pela convicção de fé religiosa -, pode resultar em interpretação equivocada, pois, o que se percebe com maior frequência, é a perspectiva antropológica e humanística, segundo a qual a prática da justiça remete à igualdade de direitos fundamentais entre os homens. O princípio e o fim da justiça é o homem. ${ }^{25}$

Em palestra em Liège, na Bélgica, em 1968 - A Pobreza na Abundância Dom Helder adverte: "É urgente incluir, na Campanha pelo Desenvolvimento do Terceiro Mundo, um capítulo essencial sobre condições de um desenvolvimento autêntico, de uma abundância inteligente e humana." E acrescenta: "o homem pode organizar a terra sem Deus, mas 'sem Deus' só a pode organizar contra o homem. Humanismo exclusivo é humanismo desumano." (CAMARA, 1968c, p.4 - grifos do autor). Não discutiremos essa questão, a saber, do desenvolvimento, em qualquer de suas vertentes, na dependência de inspiração ou de motivação divina, mas não ignoramos a existência de muitos pensadores que, mesmo na época de Dom Helder, certamente discordaram de tal perspectiva de pensamento.

De acordo com Dom Helder, quando o Stockholm International Peace Research Institute - SIPRI -, ao lado das preocupações com a guerra nuclear e com a guerra bioquímica, abriu espaço para o exame da "paz e segurança para o Terceiro Mundo", reconheceu, implicitamente, que "o desenvolvimento sendo o novo nome da paz; é urgente deixar evidente, para muitos, o que alguns começam a admitir: que o subdesenvolvimento se equipara à guerra bioquímica e à guerra nuclear." (CAMARA, 1971f, p.1)

As Religiões poderiam unir-se para completar a bela afirmação de que o desenvolvimento era o novo nome da paz. (CAMARA, 1969b, p.5) Em 1970, em viagem pelo Canadá, Suíça e USA, com palestra, provavelmente nos USA, sob o título Lições Vitais da Guerra do Vietnã, Dom Helder assegura que "as Religiões se

\footnotetext{
${ }^{25}$ Para Dom Helder, o Deus cristão não se coloca sob o princípio da necessidade. Acreditamos que Dom Helder tivesse essa consciência. Não seria um Deus carente de algo ou de alguém. Nesse sentido, Deus não iria requerer para si o princípio da justiça humana. Em outras palavras, Deus não careceria da justiça humana.
} 
preocupam, necessariamente, com a justiça, como condição para a paz". (CAMARA, 1970g, p.2) Em 1972, em conferência na cidade de Londres, Dom Helder admitiu facilidade para se chegar a algum acordo em torno da situação dos países subdesenvolvidos; contudo, reafirmou o desafio quando o que está em questão representa mudança de estruturas:

\begin{abstract}
Quando se fala a uma pessoa rica ou a um país rico, e o problema é colocado em termos de ajudas, em face de situações de pobreza ou até de miséria, o entendimento é relativamente fácil. Costuma haver boa vontade e até generosidade. $\mathrm{O}$ entendimento se torna desentendimento, o encontro vira desencontro, quando se tem a audácia de colocar os temas, em termos de direitos a reivindicar e de justiça a exigir. As injustiças não existem apenas entre indivíduos e indivíduos ou entre grupos e grupos, mas entre países e países, e até entre Continentes, entre Mundos. Sem justiça, jamais teremos paz. (CAMARA, 1972f, p.1)
\end{abstract}

As ditaduras latino-americanas prometiam desenvolvimento, em contrapartida exigiam Estado de Exceção. Dom Helder afirma que "nenhum país se arranca da miséria sem pesados sacrifícios". O dado inaceitável dessa estratégia de desenvolvimento repousa sobre o fato dos sacrifícios recaírem sobre os já desfavorecidos. Além disso, "a única maneira de participar dos benefícios do desenvolvimento implica em participar antes da criatividade e das opções". Assim,

Sustentar que o desenvolvimento se tornou de tal modo técnico que é utopia pensar em levar o povo a participar da criatividade e das opções; sustentar que o desenvolvimento, hoje, exige estado de exceção, governos fortes, ditaduras, é descrer da criatura humana e não contar com os prodígios da promoção humana, da educação libertadora. (CAMARA, 1972g, p.3)

Tal perspectiva espera postura ousada de todos os cidadãos, mas em especial dos membros da hierarquia católica. O âmbito religioso parecia ter se tornado estreito demais ante as demandas sociais, a inércia do mundo político e a indiferença da área técnica. A recomendação de Dom Helder consiste em uma mudança radical de comportamento, de envolvimento nas questões de outros campos em nome da justiça como condição real para a paz.

Percamos, de vez, o medo de parecer abandonar o terreno religioso e de invadir o terreno político e a área técnica. Percamos, de vez, o medo de parecer meter-nos em problemas internos de países estrangeiros [problemas só na aparência são internos]. Reivindiquemos, juntos, o direito e o dever de defender a criatura humana, o bem comum. Se isto é política não é política partidária, é defesa do homem; é defesa da justiça, sem a qual a paz não passa de palavra sonora. (CAMARA, 1972g, p.4) 
Diante das distorções do capitalismo - o lucro é o motor do progresso econômico e a concorrência lei suprema da economia - e do socialismo - restrições das liberdades, produção pela força, repressão da manifestação individual, desenvolvimento concentrado e distribuição desigual dos benefícios -, "é legítimo e razoável pensar em um Socialismo em que a plena socialização de cada um esteja a serviço da plena realização de todos; pensar em Socialismo, uno em seus grandes objetivos gerais, mas com variantes que atendam à cultura de cada povo." (CAMARA, 1972a, p.2) A socialização plena, para Dom Helder, passa pela autogestão, vivida por autênticas Cooperativas (CAMARA, 1972h, p.4).

No centro das preocupações de Dom Helder não se encontra o tipo de sistema econômico - capitalismo ou socialismo -, mas se determinado sistema é capaz de assegurar "justiça, como condição para a paz”. A paz é condição que se constrói nas relações entre pessoas e entre Estados. Se a paz é socialmente construída, então, faz-se necessário trabalhar pela "justiça como condição para a paz”. (CAMARA, 1975c, p.1) A paz, resultante da prática da justiça, encontra-se na dependência da mudança das estruturas em âmbito nacional - entre as pessoas e entre as instituições e organizações nacionais - e internacional - entre os Estados e entre as instituições e as organizações internacionais. A justiça não se limita à dimensão econômica da vida social, porém, a prática da justiça, na dimensão econômica, constitui-se pressuposto fundamental a partir do qual a justiça será pleiteada e/ou assegurada nas demais dimensões da vida humana e no desenvolvimento das instituições.

\section{Considerações finais}

Os escritos de Dom Helder Camara nos abrem um leque bastante amplo de possibilidades à pesquisa e à produção acadêmica. Sem lugar a dúvida, o seu pensamento serve à análise social, política, econômica, cultural e religiosa do Brasil entre os anos de 1960 e 1990. Diante dessas perspectivas, centramos nossa análise nos temas mais recorrentes em seus pronunciamentos, no exterior, entre os anos de 1968 e 1978.

Entre os principais temas desenvolvidos por Dom Helder, tendo como referência substantiva a própria realidade brasileira, identificamos: a necessidade de reformas estruturais; o combate ao colonialismo interno e externo; a integração regional e o desenvolvimento; o estabelecimento de verdadeira ordem; a promoção da justiça 
como condição para a paz. O material pesquisado nos indica outros temas igualmente importantes, quais sejam: o pseudo-embate entre Socialismo e Capitalismo, a miséria como a pior de todas as guerras, a segurança nacional, a questão ambiental, a "violência dos pacíficos", os direitos humanos.

Subjaz a todas as demandas da sociedade brasileira transnacionalizadas por Dom Helder Camara, durante a vigência do AI-5, a necessidade de reformas estruturais. A solução proposta pelo autor para uma mudança de estruturas resulta de uma educação libertadora, capaz de promover a conscientização das massas marginalizadas, com o auxílio das Comunidades Eclesiais de Base e da Teologia da Libertação. A educação libertadora constitui-se em um programa de ação das Minorias Abraâmicas, sedentas por justiça e espalhadas por todo o mundo, a ser desenvolvido segundo o método da violência dos pacíficos ou da não-violência, no intuito de exercer pressão moral libertadora.

À reivindicação de mudança de estruturas, Dom Helder não oferece elementos substitutivos claros e passíveis de adoção pela comunidade internacional. Não falta a Dom Helder, e os textos nos asseguram isso, a real percepção da profundidade das estruturas capitalistas. Contudo, parece ter escapado ao autor determinado grau de realismo para perceber que, mesmo a ONU, com poder de enforcement, não consegue, e talvez jamais consiga, empreender grandes mudanças no sistema internacional.

Os discursos, cartas e anotações feitas por Dom Helder, referentes à política nacional, não se constituíram em objeto de nossa análise, visto que alguns de seus trabalhos já foram publicados. A presente análise debruçou-se sobre as demandas da sociedade brasileira inseridas por Dom Helder em arena política internacional, durante a vigência do AI-5. 


\begin{abstract}
The article aims to analyze the main demands of transnationalized Brazilian society done by Dom Helder Camara (1909-1998), during the term of AI-5 (1968-1978). The focus of this article is on the demands of Brazilian society and not on the pastoral demands of the Church (national or international), or for the need of a Dom Helder's biography production. The historical context consists of the AI-5, a constitutional instrument which restricts the space of the actors in the domestic political arena. Under a silence imposed by the military governments of the period, the exposure of challenges of Brazilian society becomes fundamental (structural reforms, the fight against colonialism, development, social justice, etc.) in the international political arena. We witness the notion of the transnationalism beyond the borders of the country, understanding the social demands of Brazilian society as the main focus.
\end{abstract}

Keywords: Transnationalized demands; Don Helder Camara; National Politics; AI-5.

\title{
Referências
}

BAER, W. Industrialization and economic development in Brazil. Homewood: Richard D. Irwin, 1965.

ARNS, Paulo Evaristo. Brasil: nunca mais. Petrópolis: Vozes, 2001.

BRUNEAU, T. O catolicismo brasileiro em época de transição. São Paulo: Loyola, 1974.

CAMARA, H. P. Única opção, a violência? (25.04). França - Paris: mimeo, p.1-8, 1968a.

CAMARA, H. P. Violência: única opção? (25.04). França - Paris: mimeo, p.1-7, 1968b.

CAMARA, H. P. A pobreza na abundância (19.04). Bélgica - Liège: mimeo, p.1-6, $1968 \mathrm{c}$.

CAMARA, H. P. Desafio que honra uma geração (04.03). São Paulo - Brasil: mimeo, p.1-6, 1969a.

CAMARA, H. P. Os direitos humanos e a libertação do homem nas Américas (26.01). USA - New York: mimeo, p.1-6, 1969 b.

CAMARA, H. P. Esperança em uma comunidade mundial (13.01). Canadá - Winnipeg: mimeo, p.1-6, 1970a.

CAMARA, H. P. Projetos de desenvolvimento e preocupação com mudanças de estruturas (29.01). Suíça - Montreux: mimeo, p.1-6, 1970b. 
CAMARA, H. P. Impossível desenvolvimento sem juventude (20.05). Áustria Salzburg: mimeo, p.1-5, 1970c.

CAMARA, H. P. Anseios dos países sub-desenvolvidos em face das nações industrializadas (23.10). Alemanha - Bonn: mimeo, p.1-7, 1970d.

CAMARA, H. P. Contribuição da igreja para a vida social na América Latina (23.10). Alemanha - Bonn: mimeo, p.1-5, 1970e.

CAMARA, H. P. Gandhi, onde está tua vitória? Canadá, USA e Suíça: mimeo, p.1-5, 1970f.

CAMARA, H. P. Lições vitais da Guerra do Vietnã. Canadá, USA e Suíça: mimeo, p.1$5,1970 \mathrm{~g}$.

CAMARA, H. P. É tua vez, é tua hora, América Latina (24.08). Venezuela - Caracas: mimeo, p.1-8, 1971a.

CAMARA, H. P. Homem, queres ser livre? (17.07). Suíça - Friburg: mimeo, p.1-7, $1971 \mathrm{~b}$.

CAMARA, H. P. Pela paz e pela justiça entre as Américas (27.05). USA - Nashville: mimeo, p.1-6, 1971c.

CAMARA, H. P. Amigos e irmãos trabalhadores da América Latina. Participantes do VI Congresso de CLASC (21-27.11). Venezuela - Caracas: mimeo, p.1-4, 1971d.

CAMARA, H. P. Alemanha, deveis mais um exemplo ao mundo (23.05). Alemanha Wurzburg: mimeo, p.1-7, 1971e.

CAMARA, H. P. Paz e segurança para o Terceiro Mundo (11.09). Suécia - Estocolmo: mimeo, p.1-4, $1971 \mathrm{f}$.

CAMARA, H. P. Um só e grande amor (20.06). A1emanha - Munique: mimeo, p.1-3, 1972a.

CAMARA, H. P. Cristianismo entre socialismo e capitalismo (20.06). Alemanha Munique: mimeo, p.1-6, 1972b.

CAMARA, H. P. Minorias abraâmicas e estruturas da igreja (22.06). Alemanha Münster: mimeo, p.1-6, 1972c.

CAMARA, H. P. Agravante das estruturas de opressão (23.06). Alemanha - Freiburg: mimeo, p.1-7, 1972d.

CAMARA, H. P. Pacto digno de coroar vossa marcha (05.11). Itália - Florença: mimeo, p.1-7, 1972e.

CAMARA, H. P. A Igreja em face das injustiças dos nossos tempos (24.06). InglaterraLondres: mimeo, p.1-6, $1972 \mathrm{f}$. 
CAMARA, H. P. Se queres a paz, trabalha pela justiça (15.01). USA - Kansas: mimeo, p.1-5, 1972g.

CAMARA, H. P. Cristianismo, socialismo, marxismo se defrontam e se interrogam (21.06). Alemanha - Münster: mimeo, p.1-5, 1972h.

CAMARA, H. P. As macro-empresas, multi-nacionais, esfinge de nosso tempo (21.05). Bélgica - Bruxelas: mimeo, p.1-7, 1973.

CAMARA, H. P. Empresas transnacionais e mudanças de valores, hoje (06.02). Suíça Davos: mimeo, p.1-6, 1974.

CAMARA, H. P. Liberdade e justiça para todos. Canadá - Ottawa: mimeo, p.1-10, 1975a.

CAMARA, H. P. Conflitos sócio-políticos na América Latina: situação atual e perspectivas, de um ângulo pastoral (06-13.09). Peru - Lima: mimeo, p.1-5, 1975b.

CAMARA, H. P. Racismo, cancro de que livrar o mundo (18.10). USA - Davenport: mimeo, p.1-4, 1975c.

CAMARA, H. P. Nova ordem econômica internacional e perspectiva de supressão das desigualdades sociais (19-23.01). Suíça - Genebra: mimeo, p.1-7, 1976.

CAMARA, H. P. Importância de interpretar bem e viver de verdade a ética cristã (0204.10). USA - Woodlands, Texas: mimeo, p.1-4, 1977.

CASANOVA, P. G. História contemporânea da América Latina: imperialismo e libertação. São Paulo: Vértice, 1987.

CELAM. Presença ativa da Igreja no desenvolvimento e na integração da América Latina. Petrópolis: Vozes, n. 1, 1966.

CELAM. A Igreja na atual transformação da América Latina à luz do Concílio. Petrópolis: Vozes, 1968.

FURTADO, C. Desenvolvimento e subdesenvolvimento. Rio de Janeiro: Fundo de Cultura, 1961.

FURTADO, C. Dialética do desenvolvimento. Rio de Janeiro: Fundo de Cultura, 1964.

FURTADO, C. Diagnosis of the brazilian Crisis. Berkeley: University of Californian Press, 1965.

FURTADO, C. Subdesenvolvimento e estagnação na América Latina. Rio de Janeiro: Fundo de Cultura, 1966.

LIMA, L. G. S. Evolução política dos católicos e da Igreja no Brasil: hipóteses para uma interpretação. Petrópolis: Vozes, 1979. 
LOPES, J. R. B. Crise do Brasil arcaico. São Paulo: DIFEL, 1967.

LOPES, J. R. B. Desenvolvimento e mudança social: formação da sociedade urbanoindustrial no Brasil. São Paulo. Editora Nacional e Edusp, 1968.

SKIDMORE, T. Politics in Brazil: 1930-1964. New York: Oxford University Press, 1967.

SKIDMORE, T. Brasil: de Castelo a Tancredo (1964-1985). Rio de Janeiro: Paz e Terra, 1988.

SANTOS, W. G. Sessenta e quatro: anatomia da crise. São Paulo: Vértice, 1986. 